\title{
História Socioespacial Do Trabalho No Brasil, Educação Profissional E Tecnológica e a Questão Regional
}

\section{Socio-Spatial History of Labor In Brazil, Technological Professional Education and Regional Issue}

\author{
Historia Socio-Espacial del Trabajo en Brasil, Educación Profesional \\ Tecnológica y Asunto Regional
}

\author{
Castro, Cloves Alexandre de ${ }^{1}$ (Blumenau, SC, Brasil) \\ ORCID ID: https://orcid.org/0000-0001-5383-6563 \\ Plácido, Reginaldo Leandro² (Blumenau, SC, Brasil) \\ ORCID ID: https://orcid.org/0000-0001-5608-2621 \\ Schenkel, Cladecir Alberto ${ }^{3}$ (Blumenau, SC, Brasil) \\ ORCID ID: https://orcid.org/0000-0003-2609-4941
}

\begin{abstract}
Resumo
Este artigo se apresenta com a perspectiva de contribuir para o debate acerca da Educação Profissional Tecnológica no Brasil, situando sua história e, também a história socioespacial do trabalho no país a partir de sua colonização. Trata-se, pois, de um esforço pautado em pesquisa bibliográfica e reflexões no âmbito do grupo de pesquisa em Gestão, Políticas e História da Educação Profissional e Tecnológica (GPHEPT), e que procura analisar as determinantes políticas, econômicas e sociais que viabilizaram a emergência da educação profissional no contexto das disputas entre os setores produtivo agroexportador e industrial nas primeiras décadas do século XX que, de certa forma, se estende até aos dias atuais. O texto busca problematizar as dinâmicas que fizeram da Região Sudeste polo de atração de força de trabalho e concentração produtora de disparidades regionais resultantes de tais processos. A presenta-se, também, como possibilidade de contribuição para Educação Profissional e Tecnológica como política industrial e tecnológica que tenha como estratégia produzir novas dinâmicas regionais e, dessa forma, uma desconcentração regional de atração e mobilidade da força de trabalho. A territorialidade e o projeto político e pedagógico dos Institutos Federais de Educação Científica e Tecnológica apresentam-se como equipamento fixo e política de educação estratégica para o diálogo educação, tecnologia e desenvolvimento regional.
\end{abstract}

Palavras-chave: Educação Profissional Tecnológica. Trabalho. Institutos Federais. Desigualdades Regionais.

\begin{abstract}
This article presents itself with the perspective of contributing to the debate about Technological Professional Education in Brazil, situating its history and also the socio-spatial history of work in the country since its colonization. It is, therefore, an effort based on bibliographic research and reflections within the research group on Management, Policies and History of Professional and Technological Education (MPHPTE), and which seeks to analyze the political, economic and social determinants that enabled the emergence of professional education in the context of disputes between the agro-export and industrial productive sectors in the first decades of the twentieth century, which, in a way, extends to the present day. The text seeks to problematize the dynamics that made the Southeast Region a pole of attraction of the workforce and concentration of production of regional disparities resulting from such processes. It is also presented as a possibility to contribute to Vocational and Technological Education as an industrial and technological policy whose strategy is to produce new regional dynamics and, thus, a regional deconcentration of attraction and mobility of the workforce. The territoriality and the political
\end{abstract}

\footnotetext{
${ }^{1}$ Professor do Instituto Federal de Educação, Ciência e Tecnologia Catarinense. cloves.castro@ifc.edu.br

2 Professor do Instituto Federal de Educação, Ciência e Tecnologia Catarinense. reginaldo.placido@ifc.edu.br

${ }^{3}$ Professor do Instituto Federal de Educação, Ciência e Tecnologia Catarinense. cladecir.schenkel@ifc.edu.br 
and pedagogical project of the Federal Institutes of Scientific and Technological Education are presented as fixed equipment and strategic education policy for the dialogue between education, technology and regional development.

Keyword: Professional Technological Education. Job. Federal Institutes. Regional Inequalities.

\section{Resumen}

Este artículo se presenta con la perspectiva de contribuir al debate sobre la Educación Tecnológica Profesional en Brasil, situando su historia y también la historia socioespacial del trabajo en el país desde su colonización. Es, por lo tanto, un esfuerzo basado en la investigación y las reflexiones bibliográficas del grupo de investigación sobre Gestión, Políticas e Historia de la Educación Profesional y Tecnológica (GPHEPT), que busca analizar los determinantes políticos, económicos y sociales que permitieron el surgimiento de profesionales. . La educación en el contexto de las disputas entre los sectores productivos agroexportadores e industriales en las primeras décadas del siglo XX, que, en cierto modo, se extienden hasta nuestros días. El texto busca problematizar la dinámica que hizo de la Región Sudeste un polo de atracción para la fuerza laboral y la concentración de la producción de las disparidades regionales resultantes de tales procesos. También se presenta como una posibilidad de contribuir a la Educación Vocacional y Tecnológica como una política industrial y tecnológica cuya estrategia es producir nuevas dinámicas regionales y, por lo tanto, una desconcentración regional de atracción y movilidad de la fuerza laboral. La territorialidad y el proyecto político-pedagógico de los Institutos Federales de Educación Científica y Tecnológica se presentan como equipo fijo y política educativa estratégica para el diálogo entre educación, tecnología y desarrollo regional.

Palabras clave: Educación Tecnológica Profesional. Trabajo. Institutos Federales Desigualdades regionales.

\section{Introdução}

Este artigo se apresenta com a perspectiva de contribuir para o debate acerca da Educação Profissional e Tecnológica no Brasil, situando a história da educação profissional e a história socioespacial do trabalho no país, desde o momento em que foi iniciada a colonização.

Trata-se, pois, de pesquisa de cunho bibliográfico e de um esforço desenvolvido no âmbito do curso de Mestrado em Educação Profissional Tecnológica - ProfEPT, polo IFC - Blumenau, especialmente no do grupo de pesquisa em Gestão, Políticas e História da Educação Profissional e Tecnológica (GPHEPT), que procura analisar as determinantes políticas, econômicas e sociais que viabilizaram a emergência da educação profissional no contexto das disputas entre os setores produtivos agroexportador e industrial nas primeiras décadas do século $X X$.

O texto busca problematizar as determinantes que fizeram da Região Sudeste polo de atração de força de trabalho e as disparidades regionais resultantes de tais dinâmicas. Aborda de forma crítica a contribuição da Educação Profissional e Tecnológica por meio da territorialidade atual da Rede Federal de Educação Profissional Científica e Tecnológica. O texto também problematiza a tal 
territorialidade abordando a política industrial e tecnológica que proteja esses setores estratégicos no Brasil, de modo a contribuir com novas dinâmicas regionais e, dessa forma, uma desconcentração de atração e mobilidade da força de trabalho que leve ao caminho do chamado desenvolvimento socioeconômico.

$\mathrm{O}$ artigo está divido em três seções. A primeira segue a trilhas traçadas por Caio Prado Jr.(1965) em busca dos sentidos da colonização e o seu papel na constituição do capitalismo industrial e da configuração desigual do atual sistema mundo global. Dialoga ainda com Florestan Fernandes (1975), Jacob Gorender (2010) e, mais recentemente, Jessé de Souza (2017), acerca do escravismo colonial e a reordenação das relações sociais estruturantes na sociedade de classes no Brasil.

A segunda seção identifica a natureza da burguesia brasileira cuja essência é distinta da que se constituiu no continente europeu e, revela as contradições no interior do bloco do poder, entre a oligarquia paulista, mas também, oligarquias regionais insatisfeitas com a hegemonia paulista. A equação dessa contradição vai resultar na aceleração do processo de industrialização brasileira, que, por sua vez, estará amparado em uma nova proposta pedagógica e política educacional a qual a educação profissional está presente.

A terceira seção, tal como na segunda, articula as disputas políticas de controle do Estado, as políticas de educação e os agentes produtivos. Nesta parte é discutida questão do desenvolvimento e das disparidades regionais, associando dois momentos distintos da história do Brasil, quando, um projeto liberal democrático sinalizou a possibilidade de conclusão da revolução burguesa no Brasil.

\section{Escravismo colonial e as estruturas sociais no Brasil}

Pensar acerca da trajetória dos mundos do trabalho inerente às experiências e realidade brasileiras no que tange à Educação Profissional e Tecnológica e a questão regional exige uma reflexão integrada e de longa duração. Tal reflexão exige que, ao mesmo tempo, sintetize a temporalidade na compreensão e expressão do tempo no espaço, cuja essência é o que se caracteriza como processo socioespacial (SANTOS, 1977). Esta relação temporalidade-espacialidade e, consequentemente, o processo social, são constituídas por meio da relação homemnatureza a qual o primeiro se faz agente sobre a segunda por meio do trabalho e as 
marcas dessas ações materializam-se no espaço geográfico (ENGELS, 1974).

Na perspectiva de reflexão que remete a longa duração infere-se que, como afirma Caio Prado Junior (1965, p. 14), o Brasil foi exposto ao cenário mundial no bojo da transição do feudalismo para o modo de produção capitalista. Esta transição, conceituada de capitalismo comercial ou fase da acumulação primitiva de capitais, possibilitou às nações protagonistas do processo de espoliação colonial a acumularem capitais e desencadearem a revolução industrial. Isto permitiu a significativa diminuição do tempo de produção de mercadorias e a intensa mobilidade demográfica campo-cidade. Este período caracterizou, portanto, a transição em direção à fase urbana industrial, onde o excedente populacional urbano neste sistema produtivo tem o papel de regular o preço do trabalho assalariado por meio da dimensão do mercado industrial de reserva (OLIVEIRA, 1989).

Essas transformações não ocorreram de forma concomitante em todos os lugares e nações. Pelo contrário, pois as relações sociais de produção historicamente constituídas são desiguais e contraditórias por serem expressões de lutas de classes. Por isso, nos momentos de encontros entre civilizações distintas, estarão em diferentes estágios civilizatórios (MASSEY, 2008). Isto não implica alguma superioridade cultural entre elas, apesar de que a superioridade técnica-tecnológica impõe, por meio das armas, uma hegemonia cultural a qual instrumentaliza e consolida a hegemonia política e econômica em todas as escalas espaciais. A Inglaterra, seguida pela França, Alemanha e Itália foram nações ocidentais pioneiras a realizarem esse processo, por terem sido protagonistas dos processos colonial e neocolonial. Os Estados Unidos da América vem em sequência, pelo tipo particular de colonização empreendido naquele território e ao caráter liberal-burguês do campo vitorioso da Guerra Civil norte-americana (1861-1865).

Observa-se que nas nações citadas a atividade de produção mudou do sistema de trabalho escravista e servil para o trabalho assalariado. Em todas essas sociedades, mesmo com o suposto fim do trabalho escravo, o trabalho era apenas para aqueles que foram condenados pela hegemonia de classe a cumprirem a profecia da suposta expulsão do paraíso depois do suposto pecado original: 'com o suor do seu trabalho ganharás o seu pão'. Ou seja, para alimentar a minoria autorizada a viver dessas produções sociais e a se educar no cotidiano dos espaços do ócio 
acerca das questões e inquietações da natureza, da vida e da sociedade, enquanto a maioria se educava por meio da atividade laboral (LAFARGUE, 1999). Em outras palavras, parafraseando Franz Fanon, pode-se denominá-los emprestando o título de sua obra: "Os condenados da Terra" (FANON, 1979).

A transição do trabalho escravo para o trabalho assalariado no Brasil começou com pressões externas à dinastia dos Braganças. Tal transição operava interesses intimamente relacionados à comercialização dos produtos industriais ingleses e à consolidação do liberalismo enquanto ideologia da nova classe que ascendeu ao poder nos processos de revoluções burguesas. Estas revoluções burguesas, por sua vez, em dimensões diferentes varreram os resquícios feudais de grande parte do mundo europeu. A referida pressão externa coadunava na real perspectiva de aumento do mercado consumidor para os produtos ingleses e, ao mesmo tempo, forçava o Império brasileiro a caminhar no sentido da economia política e do positivismo científico que caracterizavam a estrutura epistemológica do liberalismo.

A elite imperial do Segundo Reinado brasileiro tinha a compreensão de que o negro não se prestaria ao trabalho assalariado depois dos três séculos de escravidão. Além disso, estava imbuída das ideias deterministas que justificaram a colonização na América e o neocolonialismo no século XIX, e defendia a suposta superioridade dos brancos europeus sobre os negros, índios e outros povos que habitavam a região intertropical. No Brasil a solução encontrada pela nobreza e a elite rural foi a da imigração europeia, numa clara política de branqueamento. Soma-se a isto o contexto ideológico europeu em que se dava significativa mobilidade campocidade na fase de transição demográfica e crescimento vegetativo das nações protagonistas da primeira e segunda revolução industrial.

Os imigrantes italianos, alemães, espanhóis, entre outras nacionalidades, mas, fundamentalmente essas três nacionalidades que migraram para o Brasil a partir da segunda metade do século XIX. Estes imigrantes traziam consigo uma história de expropriação nacional e alguns com a experiência urbana-industrial fabril. Traziam também a expectativa da posse da terra que os cercamentos nas suas nações de origem Ihes expropriaram e os expulsaram para as cidades, para as fábricas e para o mercado industrial de reserva. Para a elite brasileira esses imigrantes seriam 
fundamentais para o processo de desenvolvimento do país o qual se realizaria apenas com o embranquecimento da população constituída por três séculos de escravismo colonial.

\section{Burguesia industrial e educação profissional}

O processo político que colocou fim ao Império no Brasil e iniciou a República não chegou a alterar de forma significativa as relações de trabalho no campo e na cidade. Apesar da abolição formal-institucional da escravatura, fazemos coro com José de Souza Martins quando ele afirma que a abolição foi um ato de libertação dos então senhores de escravos, os quais foram indenizados e desobrigados a abrigarem o que restava de população escrava e que não chegava a $8 \%$ do total da população (MARTINS, 1979, p. 34). A significativa mão de obra de origem europeia disponível fez com que o negro compusesse o expressivo mercado industrial de reserva e inaugurasse no espaço urbano o processo de favelização.

Expoente da República da Espada e adepto do liberalismo-positivista, Rui Barbosa, nomeado ministro da fazenda por Deodoro da Fonseca, se esforçou por implantar uma política industrializante. No entanto, chocou-se com os interesses oligárquicos da elite cafeeira paulista, prestes a iniciar a dinastia por ela hegemonizada e que prevaleceu até o final do ano de 1930. É da elite cafeeira paulista que brota a essência da burguesia brasileira, do mesmo modo que é da atividade comercial a origem da burguesia europeia. Tanto uma quanto a outra foram as responsáveis para a acumulação de capitais que possibilitaram o processo de industrialização nesses respectivos espaços. Ao identificar a origem urbana de uma e a origem rural de outra se evidenciam as escalas, as dimensões e o sentido dos pêndulos do atraso e do conservadorismo de cada uma dessas burguesias, os quais terão seus reflexos no mundo do trabalho e nos sistemas educacionais de suas nações.

A educação profissional no Brasil, nos moldes de uma rede de escola e como projeto nacional, surge no contexto da República, a partir do Decreto n. ${ }^{\circ} 7.566$, de 1909, assinado pelo presidente Nilo Peçanha. Por este decreto foram criadas em diferentes unidades federativas, sob a jurisdição do Ministério dos Negócios da Agricultura, Indústria e Comércio, dezenove 'Escolas de Aprendizes Artífices' 
destinadas ao ensino profissional, primário e gratuito (BRASIL, 1909). O objetivo de criar aquelas escolas foi o de formar operários e mão de obra, através do ensino prático-repetitivo e conhecimentos técnicos básicos necessários à execução, de forma mecânica, de um ofício (ALVES, PLACIDO, FARIA, RHOR, 2019, p. 568).

É necessário pontuar que o ensino profissional, na perspectiva do Decreto n. ${ }^{\circ} 7.566$, figurava mais no plano assistencial do que num programa propriamente educacional. Desta forma, enquanto aos filhos das elites se configurava um projeto de ensino superior, para os pobres restava educação profissional de caráter assistencial, reafirmando as relações de poder herdadas da colônia e do império e de suas bases escravocratas estruturais. Apesar de avanços ocorridos nas políticas educacionais a partir da proclamação da República, a educação profissional no Brasil não perdeu seu caráter assistencialista, pois como se observa no texto do decreto:

\begin{abstract}
[...] que o aumento constante da população das cidades exige que se facilite às classes proletárias os meios de vencer as dificuldades sempre crescentes da luta pela existência; que para isso se torna necessário, não só habilitar os filhos dos desfavorecidos da fortuna com o indispensável preparo técnico e intelectual, como fazê-los adquirir hábitos de trabalho profícuo, que os afastará da ociosidade, escola do vício e do crime; que é um dos primeiros deveres do Governo da República formar cidadãos úteis à Nação" (BRASIL. Decreto $\mathrm{n}^{\circ} 7.566$, de 23 de setembro de 1909).
\end{abstract}

Impossível compreender as nuances da Educação Profissional e Tecnológica no Brasil sem destacar determinações e disputas dos projetos de nações enredados na formação do Estado nacional brasileiro. Trata-se de disputas cujas bases são as estruturas produtivas que constituíram a base material da sociedade brasileira que se estruturou de modo a abastecer o mercado externo de gêneros de baixo valor agregado e, ao mesmo tempo, adquirir desse mesmo mercado manufaturados e tecnologias com significativo valor agregado. A diferença de valor das mercadorias reside na densidade técnica e tecnológica contida nas suas determinações, além de outros elementos que de acordo com a economia política constituem o valor.

Os desfechos das disputas dos projetos de nação deu fim à Primeira República brasileira (1889-1930) por meio da constituição e fortalecimento de novo campo político cuja origem está na dissidência das oligarquias regionais que compunham o bloco histórico anterior, mas que dele era preterido pela hegemonia 
paulista. Este grupo hegemônico se revezava no poder de modo desigual com a oligarquia mineira e inviabilizava o desenvolvimento do setor industrial ao capturar o fundo público para os interesses da economia cafeeira paulista (OLIVEIRA, 2003).

A crise de superprodução associada à contenção do consumo que resultou no colapso global do capitalismo em 1929 contribuiu para pôr fim à hegemonia paulista-cafeeira no interior do bloco de poder. Tal hegemonia já vinha sendo arranhada durante a década de 1920 e a formação do Partido Democrático (PD), em 1926, demonstrou que o setor modernizante da burguesia paulista movimentava-se para estimular a capacidade produtiva industrial que vinha sendo inviabilizada desde a ascensão de Prudente de Moraes, em 1894 (BOITO, 1982). Sobre esse aspecto, o sociólogo Francisco Oliveira contribui acerca do debate sobre a industrialização brasileira, com a tese da industrialização por substituição de importações e a industrialização pela necessidade de produção (OLIVEIRA, 2003).

Em trabalho seminal Warren Dean considera as casas de importações as origens econômicas e sociais do empresariado brasileiro e defende que as atividades do complexo cafeeiro, das indústrias e das casas importadoras eram, na maioria das vezes, realizadas concomitantemente pelos mesmos agentes sociais, e tiveram suas origens na acumulação cafeeira e na propriedade da terra (DEAN, 1991). Dean demonstra que o mercado centralizava as atividades das casas importadoras e que em pouco tempo começaram a investir na produção de similares até então importados para o abastecimento da demanda interna e, consequentemente, aceleraram e diversificaram o processo de industrialização. Esse autor vê a industrialização brasileira como resultado do processo de industrialização por substituição de importações. Dean ainda destaca que a familiaridade dos comerciantes importadores com o mercado consumidor de manufaturados e com produtos industriais abriu as portas para que produzissem, eles próprios, as mercadorias que mandavam buscar no exterior.

Tributário da tradição clássica marxista de interpretação do Brasil que concebeu a formação do país desde o início no contexto da expansão do capitalismo comercial europeu, o sociólogo Francisco Oliveira contesta a tese de viés estruturalista. Importante lembrar que, a partir desta perspectiva, compreende-se a industrialização brasileira como resultado da substituição de importações e de que o 
desenvolvimento do capital e sua valorização se realizariam no mercado com a dinâmica dos preços. Nesse sentido, para Francisco Oliveira, a tese de substituição de importações entendeu a industrialização brasileira pautada nas necessidades de consumo, e não nas necessidades de produção cuja potencialidade estava contida a partir do uso do Estado para a satisfação de interesses de classe da hegemonia cafeeira (OLIVEIRA, 2003). Francisco Oliveira esclarece ainda que a expansão capitalista no Brasil se efetivava por meio da introdução de novas relações nas formas arcaicas de produção, e, ao mesmo tempo, diante da reprodução do arcaico por meio dessas novas relações, produzia desta forma um processo de desenvolvimento desigual e combinado.

No que se refere à questão das classes sociais, a análise de Francisco Oliveira introduz no debate, sobre a expansão do capitalismo no Brasil, os atores sociais e seus respectivos campos políticos e ideológicos. Situa ainda o processo da chamada Revolução de 1930 como um dos 'novos' elementos de reprodução da arcaica estrutura de poder do Estado brasileiro. Nesta abordagem as novas formas de reprodução capitalista exigiram também modernas formas de relacionamentos entre o capital e trabalho, somente possíveis com um viés mais moderno do Estado, mesmo que oriundo das oligarquias históricas que operam o país desde os primórdios da colonização. Foi desta forma, pois, que de acordo com o autor em questão, o Brasil introduziu as bases econômicas e materiais da industrialização (fixação do salário mínimo e a formação do programa de produção de bens de consumo duráveis e de capital) e rumou para a modernização capitalista.

Como parte desse fenômeno de reprodução do arcaico através de 'novos' elementos na estrutura do poder, surgiram também outros elementos nos campos cultural e educacional e que já despontavam antes mesmo da emergência de Vargas ao poder. Trata-se da versão brasileira do Movimento da Escola Nova que resultou na publicação do Manifesto dos Pioneiros da Educação de 1932. Tal documento representou a ruptura com o arcaico no campo educacional. Neste sentido setores da burguesia brasileira compreendiam necessário um esforço de centralização para tratar a educação como questão nacional e objeto de regulamentação nos seus diferentes níveis e modalidades por parte do Estado. Além disso, havia um clamor para outras transformações no intuito de superar o ensino tradicional relacionado com as velhas 
estruturas que estavam sendo superadas pelas transformações nos campos político e econômico (SAVIANI, 2013).

Esse movimento ia de encontro à modernização caracterizada pela indústria e tinha como essência a compreensão de que se fazia necessária uma organização ou um sistema educacional capaz de preparar a sociedade brasileira para os novos desafios do mundo do trabalho que chegavam com a intensificação do processo de industrialização. Por outro lado, a reprodução do arcaico no que se refere aos aspectos necessários para a estabilidade da nova ordem que se consolidava, estava presente nas disputas no interior do próprio movimento escolanovista nacional acerca da obrigatoriedade do ensino religioso. Como demonstra Saviani,

[...] a Igreja já estava contemplada no projeto de hegemonia da burguesia industrial, conforme manifestação inequívoca de Roberto Simonsen. Para ele a Igreja estava destinada a desempenhar um grande papel de esclarecimento sobre as necessidades do país, "explicando à massa sofredora que o seu estado atual não decorre dos casos, da compressão exercida pelas classes mais favorecidas" (SAVIANI, 2013,p. 196-197).

O decreto n. ${ }^{\circ} 19.941$, de 1931, introduziu pela primeira vez na história republicana a obrigatoriedade do ensino religioso nas escolas oficiais e atendeu a pressões intensas da Igreja. Tal contradição iria se acirrar quando da divulgação do Manifesto dos Pioneiros, que continha debates acerca dos fundamentos e finalidades da educação, cuja centralidade deveria passar a ser o aluno. Quanto a organização e administração do sistema educacional os signatários do manifesto explicitavam o protagonismo do Estado acerca de uma educação essencialmente pública, laica, gratuita e obrigatória (SAVIANI, 2013, p. 241). De acordo com Saviani (2013), para Fernando Azevedo, o ideal da Escola Nova envolvia três aspectos: escola única, escola do trabalho, escola-comunidade.

A proposta de experiência de ensino voltado aos interesses e necessidades do aluno contida no Manifesto de 1932 está indissociável dos rumos políticos e econômicos que o país seguira pós-movimento revolucionário de 1930, da efetivação do fortalecimento da tendência industrializante da burguesia nacional e do movimento migratório campo-cidade. A novidade trouxe para o cenário da educação nacional um sistema educacional público e laico cuja pauta ainda permeia nas reivindicações atuais, o que demonstra ter havido durante todos esses anos, no interior do próprio movimento liberal democrático, uma contradição que inviabilizou a realização de tais 
pautas. Por outro lado, a pauta das demandas associadas à base produtiva realizouse e tem se redefinido na medida em que tal base produtiva se reconfigura, reestruturando a chamada "hierarquias das capacidades" dos saberes. Esta hierarquia era materializada no conceito e concepção de meritocracia, contidos no Manifesto dos Pioneiros de 1932, e que também acompanharam as demais reformas educacionais posteriores.

Tais hierarquias, fundadas no suposto caráter biológico que permitiria a cada indivíduo aprender até onde possibilita as suas aptidões naturais independentemente das determinantes de ordem socioeconômica ou de classes sociais, pois, todos seriam contemplados com as mesmas oportunidades educacionais. Na prática, ao mesmo tempo, em que os pioneiros da educação cumpriram o importante papel de inserir no debate nacional a educação pública e obrigatória, também contribuíram para hierarquizá-la, produzindo e acentuando desigualdades por meio da suposta hierarquia das aptidões as quais não estão desvinculadas das classes sociais e das condições de vida que os lugares que se ocupa no processo de produção da base material da sociedade possibilitam. Destarte, Saviani procura demonstrar que

[...] a Escola Nova busca organizar a escola como um meio propriamente social para tirá-la das abstrações e impregna-la da vida em todas as manifestações. [...] propiciando a vivência das virtudes e verdade morais, estará contribuindo para harmonizar os interesses individuais e coletivos. [...] na sociedade moderna a família, que deixou de ser o centro de produção para ser simplesmente um centro de consumo, vem transferindo a função educativa para o Estado. A educação tornou-se uma função essencialmente e primordialmente estatal. [...] considerando-se que o direito do indivíduo à educação se funda na biologia, o Estado deve organizar a escola e torná-la acessível, em todos os seus graus, a todos os seus cidadãos, independentemente de suas condições econômicas e sociais. Eis o princípio da "escola única". Considerando, no entanto, que, no regime político brasileiro, - Estado não poderá impedir que as classes mais privilegiadas recorram a escolas privadas para oferecer aos seus filhos uma educação de classe diferenciada, o "Manifesto" propõe a aplicação desse princípio à escola oficial destinada a todas as crianças dos 7 aos 15 anos. Esta seria a escola pública que asseguraria uma educação comum, igual para todos (SAVIANI, 2013, p. 245).

É sobre as bases desses fenômenos políticos, econômicos e educacionais, os quais podem ser denominados de socioculturais, ao considerar cultura tudo o que o homem, enquanto ser social produz, que ocorrera durante cerca de quatro a cinco décadas um violento processo de mobilidade campo-cidade intra e inter-regional e que produzirá um dos mais importantes fluxos migratórios do país: Nordeste - 
Sudeste. A consequência destes fluxos é o aumento das disparidades regionais devido à concentração da base industrial no espaço o qual o capital que até então era mobilizado para a reprodução do complexo cafeeiro passou a ser alocado por agentes oriundos da própria burguesia cafeeira modernizada, para os interesses da indústria.

Em outras palavras, pode-se dizer que naquele momento, parte da burguesia oligárquica paulista saltou escalas e passou a empreender para além da produção de café e das casas importadores, assumindo a necessidade da produção industrial contida desde o início da República Oligárquica. Para viabilizar a operação da nova base produtiva material que se constituía com o avanço da industrialização fazia-se necessário um novo tipo de formação oferecida por um novo sistema escolar. Tal sistema era reivindicado pelo documento dos pioneiros da educação que representava a expressão pedagógica da revolução burguesa que se consolidava com o movimento de 1930 (SAVIANI, 2013).

Em estudo sobre o desenvolvimento urbano paulista, Maria Flora Gonçalves analisa duas questões fundamentais e articuladas consideradas como chave explicativa da constituição urbana paulista e do papel histórico assumido pelo estado de São Paulo no desenvolvimento econômico nacional. A primeira é a relação entre a cidade de São Paulo e a rede urbana que se configurava a partir dela; a segunda implica avaliar o papel estratégico do desenvolvimento urbano na passagem da economia cafeeira para industrial (GONÇALVES, 1998). Ela nos conduz para as distintas urbanizações surgidas a partir das estruturas produtivas (cafeeira e industrial) que viabilizaram a reprodução do capital e, concomitantemente, do trabalhador. Indica também a necessidade da produção de um sistema educacional para além do tradicional, para viabilizar os desafios das transformações que se efetivavam sob uma rica rede urbana de que a cidade de São Paulo foi polo aglutinador, mas que também se fez presente em outras cidades da região sudeste.

O complexo cafeeiro foi responsável pela composição urbana das cidades em que a cultura cafeeira se expandiu e os barões do café exerceram sua hegemonia política e cultural. Lugares onde se estabeleceu uma moderna superposição de técnicas a qual constituiu, comparando ao todo do território brasileiro, uma moderna base material a qual com a crise do complexo cafeeiro a indústria vai se assentar. Nas palavras de Brandão, a 
[...] reprodução ampliada do complexo cafeeiro paulista estruturará um "novo urbano" no estado e no país. Essa reprodução exigirá um segmento urbano para sua ampliação e diversificação. O café plantará cidades. Novas funções urbanas serão impostas pela acumulação cafeeira, que possuía múltiplas faces: café, ferrovias, bancos, comércio, infra-estrutura etc. Todas essas faces serão sintetizadas no espaço urbano, cada vez mais diferenciado e dinâmico (BRANDÃO, 2007, p. 109).

Nesse sentido, a série de reformas educacionais, nos diferentes níveis, instituídas pelo governo revolucionário que teve Francisco Campos à frente do Ministério da Educação e Saúde, inaugurou a legislação acerca da organização de cursos e percursos de profissionalização visando à superação da hegemonia agrária exportadora. Schenkel aponta que:

No início dos anos de 1930 foram criados os Ministérios da Educação e Saúde Pública e do Trabalho, Indústria e Comércio, e, também, o Conselho Nacional de Educação - CNE. Francisco Campos assumiu o Ministério da Educação e Saúde Pública e iniciou uma série de reformas na educação, em todos os níveis. Essa reforma educacional ficou conhecida como a "Reforma Francisco Campos", com destaque aos Decretos Federais $n^{\circ}$. 19.890/1931 e $n^{\circ}$. 21.241/32, que regulamentaram o ensino secundário, e o Decreto Federal $n^{\circ}$. 20.158/31, que organizou o ensino profissional comercial, cuja importância se deve ao fato de "[...] ser o primeiro instrumento legal a estruturar cursos já incluindo a ideia e itinerários de profissionalização" (SCHENKEL, 2012, p. 118).

O desenvolvimento industrial desigual, contraditório e combinado brasileiro cuja base estrutural é o território paulista e as determinações técnicas que assentam e sobrepõem-se à sua base material, vai acentuar as desigualdades regionais e fortalecer as oligarquias regionais ao ponto de fazer das fragilidades regionais consequências da concentração industrial no território paulista, condição de barganha e discurso regionalista de captura privada do fundo público com o argumento de sanar tais desigualdades regionais que acabam fortalecendo essas oligarquias locais e estimulam o êxodo rural e inter-regional em direção ao Sudeste, particularmente o eixo São Paulo-Rio de Janeiro, regiões polarizadoras (OLIVEIRA, 2003).

É importante ter claro que o Movimento Escola Nova, inaugurado no Brasil, com o Manifesto dos Pioneiros, não era um todo homogêneo. Tal como a burguesia brasileira, continha em seu interior algumas frações associadas a interesses de ordem corporativistas e/ou cultural, como os interesses do ensino privado (também ligado à Igreja), como a concepção da hierarquia das competências que fortalecia uma educação para os que iriam para os chãos das fábricas e outra educação para os 
oriundos de famílias abastadas, que iam para as universidades (SAVIANI, 2013). É nesse contexto que emerge por meio da Reforma Capanema, um conjunto de legislações de educação para o trabalho que agrega os setores agrícola, comercial e industrial. De acordo com Schenkel,

\begin{abstract}
A Reforma Capanema (1942-1943) pode ser entendida como resultante da intensificação das cobranças para a promoção de mudanças educacionais e do aquecimento dos debates a respeito dos rumos da educação, visando a sua adequação ao contexto político, econômico e social e o atendimento dos interesses econômicos da época. [...] No mesmo período foi instituído o serviço de aprendizagem profissional e foram criadas as instituições especializadas para esse fim, tais como o Serviço Nacional de Aprendizagem Industrial - SENAI, em 1942, e o Serviço Nacional de Aprendizagem Comercial - SENAC, em 1946. Além disso, em 1942, o governo estabeleceu, por meio de Decreto Lei, o conceito de menor aprendiz para os efeitos da legislação trabalhista (CNE/CEB, 1999a). Nesse mesmo contexto, ainda, por meio do Decreto-Lei $n^{\circ}$. 4.127, de 25 de fevereiro de 1942, foi constituída a rede federal de estabelecimentos de ensino industrial, composta por escolas técnicas, escolas industriais, escolas artesanais e escolas de aprendizagem. O referido Decreto também promoveu a transformação das Escolas de Aprendizes e Artífices em Escolas Técnicas ou em Escolas Industriais (SCHENKEL, 2012, p. 120).
\end{abstract}

No entanto, é importante ponderar que as ações concernentes à efetivação da pauta objetivada por esse cabedal legislativo serão mais efetivas e concretizadas após o término da Segunda Guerra e a pacificação nacional em busca do equilíbrio e a unificação dos democratas e progressistas (SAVIANI, 2013).

O período democrático getulista (1951-54) e a inflexão nacional desenvolvimentista refletiram nas disputas pelos rumos da educação nacional cujo momento, 1947-1961, Saviani (2013, p. 277) denominou de predominância da pedagogia nova. Tal equação possibilitou ajustes/equivalências que passaram a permitir a quem concluísse os cursos técnicos,

[...] a candidatura em cursos superiores, desde que fossem aprovados em exames de complementação das disciplinas não cursadas no segundo ciclo do secundário; como, também, aos egressos do primeiro ciclo dos ramos profissionais do ensino médio (pós-primário), para ingresso no segundo ciclo do ramo secundário, que propiciava a candidatura irrestrita ao ensino superior (SCHENKEL, 2012, p. 121).

Tal desfecho deve ser compreendido, por um lado, como expressão do enfraquecimento do campo que hegemonizou o debate educacional durante os quinze primeiros anos do governo oriundo da Revolução de 1930; por outro lado é também demonstração da intensificação da dinâmica urbana indissociável do êxodo rural, 
alimentada pela concentração fundiária e a acelerada industrialização.

$\mathrm{Na}$ esteira dos '50 anos em 5', da abertura para as montadoras internacionais se instalarem no país e da consequente influência da capital financeiroindustrial no Brasil no contexto da Guerra Fria, no governo Juscelino Kubistchek, consolidou e acentuou-se um certo modelo de produção de bens e serviços. Este modelo se fez hegemônico no estado de São Paulo (por se tratar do polo da região concentrada) e que explica a generalização de aspirações educacionais voltadas para a realização de expectativas de ascensão social vertical, estimuladas pelas mudanças do mercado de trabalho.

Estas perspectivas encontram canais de expressões como o do Movimento em defesa da escola pública, que teve entre suas grandes referências o sociólogo Florestan Fernandes e veteranos signatários do Manifesto dos Pioneiros, como Anísio Teixeira As mesmas perspectivas provocou o alargamento da oferta de oportunidades escolares, que por sua vez, conduziu às alterações na organização e funcionamento de todo o ensino de nível médio.

Em 1959, no contexto do manifesto 'Mais uma vez convocados', onde se reafirma os princípios dos pioneiros de 1932, como o da escola pública e gratuita para todos. O documento dedica um tópico chamado "Educação para o trabalho e Desenvolvimento Econômico" e defende a sintonia da educação com as transformações e características da sociedade em que está inserida, dessa forma, constituindo-se como instrumento e parte do desenvolvimento. Saviani (2013, p. 295) assinala que o manifesto aponta que as transformações de base científico-tecnológica já estavam exigindo que a escola, em lugar de ciência pura e desinteressada, se volte para objetos mais práticos, variados e mais profissionais e de ciência aplicada. No ano de 1959, período da república populista de Juscelino Kubitschek, as Escolas Industriais e Técnicas são transformadas em autarquias com o nome de Escolas Técnicas Federais (SOUZA, 2011). As instituições ganham autonomia didática e de gestão.

O acúmulo resultante das lutas da década de 1950 acerca do debate do desenvolvimento brasileiro e a questão da educação como elemento central resultou na Lei de Diretrizes e Bases da Educação (LDB), em 1961. Sobre essa lei, Schenkel esclarece que: 
Em 1961, por meio da Lei Federal n. 4.024, de 20 de dezembro de 1961 (BRASIL, 1961), foram estabelecidas as Diretrizes e Bases da Educação Nacional pela primeira vez. Essa Lei, dentre outros aspectos, estabeleceu a plena equivalência entre os cursos de mesmo nível, sem a necessidade de exames e provas de conhecimentos, ao equiparar o ensino profissional, do ponto de vista da continuidade de estudos, para todos os efeitos, ao ensino acadêmico. Com essa Lei, ao menos formalmente, foi superada a dualidade entre ensino para as "elites" e ensino para os "desvalidos da sorte" (SCHENKEL, 2012, p. 122).

Com isso o ensino técnico nas modalidades agrícola, industrial e comercial passou a ser organizado nos ciclos ginasial no período de quatro anos, e colegial, de no mínimo três anos. Junto às disciplinas dos cursos técnicos foram inseridas quatro disciplinas do ginasial secundário e no segundo ciclo, cinco do colegial secundário, havendo uma optativa nos referidos ciclos (SCHENKEL, 2012). A lei n. ${ }^{\circ} 5.540$ de 28 de Novembro de 1968, revogada com a promulgação da atual LDB, em Dezembro de 1996, deu vida aos Cursos Superiores de Tecnologia, organizados no âmbito das Escolas Técnicas Federais já no ano de 1969.

Se de um lado respondia a certa reivindicação social pelo acesso ao ensino superior, bandeira do movimento estudantil duramente reprimido; por outro lado, respondia também às demandas do milagre econômico que faz o país experimentar taxas de crescimento econômico que variaram 7\% a 12\% entre os anos de 1968-1973, e viu a sua população urbana ultrapassar a população rural em 1970, por meio da significativa e violenta mobilidade inter-regional Nordeste-Sudeste, particularmente para os estados do Rio de Janeiro e São Paulo e, evidentemente, majoritariamente para o segundo pelas questões históricas que o fez centro de polarização nacional, o que acelerou e acentuou as desigualdades regionais (SINGER, 1976).

Se o foco da reforma de 1968 , executada a partir da lei $n .^{\circ} 5.540$, foi no ensino superior, logo, no que tange ao ensino médio não tardaria a aparecer. A lei $n$. $^{\circ}$ 5.692, de 11 de Agosto de 1971 estipulou novas normas para os ensinos de $1^{\circ}$ e $2^{\circ}$ Graus e determinou obrigatório o ensino de $2^{\circ}$ grau profissional, o que hoje chamamos de ensino médio.

A Educação Profissional técnica, assim, deixou de ser realizada por escolas especializadas e recaiu sobre a responsabilidade dos sistemas estaduais de ensino, os quais, além de enfrentarem a expansão de oferta do ensino de Primeiro Grau, viram-se às voltas com problemas de ordens diversas para implantar os cursos técnicos de Segundo Grau, dentre os quais se destacam: falta de estrutura física das escolas, falta de equipamentos para os 
laboratórios e as práticas, falta de pessoal para a composição dos quadros docentes, dentre outros (SCHENKEL, 2012, p. 124).

Através de documento da Câmara de Educação Básica do Conselho Nacional de Educação (CNE/CEB, 1999a), Schenkel (2012, p. 123-124), pontua que essa reforma deixou profundas marcas na educação profissional, percebidas até os dias atuais. Entre elas estão a ausência de preocupação com conteúdos da formação de base; a desorganização das redes públicas que ofereciam o ensino técnico e a descaracterização do ensino secundário e normal dos estados e municípios; e, a estimulação da falácia de que a formação profissional seria a resolução para as questões relacionadas ao emprego, já, no bojo da crise do milagre econômico.

No início da década de 1980 a Lei n. ${ }^{\circ} 7.044$, de 18 de Outubro de 1982, tornou facultativa a profissionalização no $2^{\circ}$ grau e as escolas que ofereciam esse nível de ensino ficaram livres da obrigatoriedade prevista na lei n. ${ }^{0} 5.692 / 71$ e, nas palavras de Schenkel (2012, p. 124) "[...] reverteram seus currículos para o ensino acadêmico e, em alguns casos, acompanhado de um arremedo de profissionalização", e continua que naquele contexto "[...] a oferta de cursos profissionalizantes acabou por se restringir às escolas especializadas [...] e, trouxe como resultado falsas expectativas em relação a difusão caótica de habilitações profissionais sem identidade própria".

\section{A Burguesia Perdeu o Trem ou a Dependência Consentida é um Projeto?}

De acordo com a série histórica do IBGE no período de 1947 a 2013, o ápice da participação da indústria de transformação brasileira no PIB foi o ano de 1985, quando chegou a 30\%. Quando os impactos da crise econômica atual (associada à crise política interna) atingiu a economia brasileira, em 2013, a participação a que nos referimos estava em 12,5\%. Nesse contexto cabe a questão: quais foram as determinantes do esfacelamento da indústria brasileira cujo ápice foi o ano de 1985 com sua trajetória intimamente relacionada ao investimento público? Como essas questões relacionam-se com a educação profissional e o desenvolvimento regional?

Responder a essas questões não é tarefa fácil e não há possibilidade de haver respostas certeiras diante de universos de concepções contraditórias. No 
entanto, aponta-se que a raiz do problema está na estrutura escravocrata colonial a qual a base material da sociedade brasileira está assentada e a sua burguesia a reproduz de modo a continuar senhorial no esboço de uma democracia liberal (SOUZA, 2017). Depreende-se desta forma que a reprodução do subdesenvolvimento no Brasil é estratégia política de reprodução das elites históricas no poder por meio da compactuação de uma espécie de Pacto Colonial moderno e que assegura ao país lugar semelhante ao que a Colônia ocupava, tal como à burguesia brasileira, lugar semelhante ao da elite colonial escravocrata.

A partir do Pós-Segunda Guerra Mundial foi moldando-se ao que o geógrafo brasileiro Milton Santos chamou de meio técnico científico informacional. Essa nova fase do capitalismo superou a base material taylorista-fordista das duas primeiras revoluções industriais no que tange à forma de produzir. Entretanto, não a eliminou, pois, têm nelas as suas determinações e o desenvolvimento desigual e combinado possibilita a convivência de modo desigual de formas de produção pretéritas e presentes.

De acordo com Santos, essa união entre a técnica e a ciência, que caracteriza o que também é chamado de Terceira Revolução Industrial, vai se apresentar sob a égide do mercado.

E o mercado, graças exatamente à ciência e a técnica, torna-se um mercado global. A idéia de ciência, a idéia de tecnologia e a idéia de mercado global devem ser encaradas conjuntamente e desse modo podem oferecer uma nova interpretação à questão ecológica, já que as mudanças que ocorrem na natureza também se subordinam a essa lógica. [...] os objetos técnicos tendem a ser ao mesmo tempo técnicos e informacionais, já que, graças a extrema intencionalidade de sua produção e de sua localização, eles surgem como informação; [...] a energia principal de seu funcionamento é também a informação. [...] quando nos referimos às manifestações geográficas decorrentes dos novos progressos, não é mais de meio técnico que se trata. Estamos diante da produção de algo novo, a que estamos chamando de meio técnico-científico-informacional (SANTOS, 1999, p. 190).

A manifestação desse novo meio técnico no Brasil passou a se dar quando ainda não havia se completado no território brasileiro as transformações na base material do meio técnico anterior, ou seja, a nova industrialização de base tayloristafordista e dependente tecnologicamente das grandes montadoras e indústrias químicas internacionais desde o final da década de 1950 e acentuada com o regime militar (1964-1985). Quando o Brasil não autonomizou a produção daqueles bens de 
consumo que as multinacionais vieram produzir no território brasileiro devido ao custo da mão de obra, quando a base produtiva começa a mudar, os números de empregos no setor da indústria de transformação começam a cair e o país não completa a transformação iniciada com a Revolução de 1930. De igual forma, o país não teve condições de avançar à moderna base material técnica-científica-informacional, Ihe restando assim o mero e servil papel de suprir a demanda do centro do capitalismo por commodities.

Esse cenário contém fenômenos caros à história recente do Brasil: Nova República; eleições presidenciais de 1989 após 29 anos da última eleição presidencial; a desindustrialização da região metropolitana de São Paulo e a incapacidade de se viabilizar a desconcentração regional industrial; o impedimento do governo Collor e o adiamento da primeira tentativa neoliberal no país; o Consenso de Washington e o consenso no Brasil por uma coalização de centro-direita em torno de Fernando Henrique Cardoso para inserir o Brasil na nova ordem mundial na forma a qual sempre esteve no mundo; e por fim, a promulgação da LDB (Lei n. ${ }^{0}$ 9.349/96) possível diante dos conflitos e contradições do processo que se estendia desde a luta pela constituinte, concomitante ao Movimento das Diretas Já.

A Lei n. ${ }^{\circ}$ 9.394, de 20 de dezembro de 1996, no que se refere à Educação Profissional foi idealizada de modo a organizar e a articular às diversas formas de educação, trabalho, ciência e tecnologia com o ensino regular. Schenkel demonstra que a

[...] articulação com o ensino regular, em seus diversos níveis, significou uma compreensão, ao menos do ponto de vista legal, inteiramente nova. A título de comparação, a Lei $n^{\circ}$. 5.692/71 tratava esse ramo como ensino técnico e integrado ao ensino de $2^{\circ}$ Grau. Esse novo dispositivo abriu a possibilidade, formalizada nos Decretos $n^{\circ}$. 2.208/97 e $n^{\circ}$. 5.154/2004, de formação profissional em três níveis: básico ou qualificação profissional, sem exigência de escolaridade mínima; técnico, destinado à habilitação profissional técnica, com a exigência de conhecimentos do ensino fundamental e realizado de forma integrada, concomitante ou subsequente ao ensino médio; e tecnológico, formação em Educação Profissional de nível superior e com a "exigência" de conhecimento do ensino médio, portanto, tendo-o concluído. Isto é, os Cursos Superiores de Tecnologia passaram a ter as mesmas exigências e prerrogativas da graduação em Educação Superior [...] (SCHENKEL, 2012, p. 125-126).

No entanto, no momento em que foi sancionada a LDB a participação da indústria de transformação brasileira no PIB estava na casa dos $14 \%$ e vivia-se a crise do Plano Real, alimentada pela quebra do sistema financeiro nacional que levou à 
lona bancos como o Econômico, o BCN, o Nacional e o Bamerindus. No mesmo contexto produtos industriais chineses começavam a ganhar espaço no mercado consumidor brasileiro, o qual agonizava com uma política de combate à inflação associada a arrocho salarial e contenção de consumo.

Foi por meio da conquista da LDB que se promoveu a superação do enfoque assistencialista atribuído à Educação Profissional, sintetizado na expressão os "desvalidos da sorte". Mas foi a experiência do Projeto Democrático Popular, de 2003 - 2016, que procurou dar um sentido geoestratégico e de desenvolvimento regional à Educação Profissional, a partir de compromissos históricos com projetos de educação e educação profissional integrada, em meio a imensas e intensas contradições no interior deste próprio projeto popular e em seu exterior, na forma de combate oculto e em outros momentos, radicalmente declarado. Porém, é em meio à execução desse projeto de Educação Profissional que a Rede Federal de Educação Profissional e Tecnológica dá um salto fenomenal no que se refere à expansão de suas unidades.

Criados em 2008, pelo então presidente Luiz Inácio Lula da Silva, os Institutos Federais de Educação, Ciência e Tecnologia (IFs) tem como fundamento a verticalização do ensino (BRASIL, 2008). Esse tipo de organização educacional permite que os docentes atuem em diferentes níveis de ensino e que os discentes participem ativamente em diferentes espaços de aprendizagem.

Em 2020, passados 111 anos do decreto de Nilo Peçanha e 10 anos da criação dos IFs, estes estão distribuídos em 589 campi e atuam junto com outras instituições para atender à demanda educacional em todos os Estados e regiões do País. Os IFs oferecem 10.643 cursos e contabilizam 947.792 matrículas, segundo a Plataforma Nilo Peçanha (MORAES, et al., 2018), que apresenta um panorama de toda a Rede Federal de Educação Profissional, Científica e Tecnológica vinculada ao Ministério da Educação (MEC).

A proposta pedagógica dos IFs busca articular trabalho, ciência e cultura na perspectiva da emancipação humana. É dessa forma que sua orientação pedagógica recusa o conhecimento pronto, baseado meramente em livros didáticos, buscando uma formação profissional mais abrangente e flexível, com menos ênfase na formação para o trabalho mecânico e mais na compreensão do mundo do trabalho 
e em uma participação qualitativamente superior. Trata-se de um profissionalizar-se mais amplo, que abre infinitas possibilidades de reinventar-se no mundo e para o mundo. Princípios que são válidos e quistos para qualquer campo de formação.

\section{Conclusão}

A Rede Federal de Educação Profissional e Tecnológica foi interiorizada na perspectiva de estimular o desenvolvimento regional, conter mobilidades interregionais e estimular a desconcentração industrial nas regiões tradicionalmente polarizantes, como o Sudeste brasileiro, particularmente São Paulo e Rio de Janeiro.

Destarte, nos ensina Marx (1971) que a história se apresenta como tragédia em um momento e no segundo como farsa. Vivemos atualmente no Brasil uma encruzilhada semelhante à que narra Francisco Oliveira diante da experiência da Superintendência do Desenvolvimento do Nordeste (SUDENE), em sua obra seminal 'Elegia para uma re(li)gião: SUDENE, Nordeste. Planejamento e conflitos de classes', expressão de um verdadeiro esforço de pensar a região e o planejamento regional, de modo a apresentar alternativas para uma questão cara ao desenvolvimento brasileiro e à reprodução das oligarquias locais por meio do regionalismo e a apropriação por estes do instrumento de planejamento para operarem os seus próprios interesses e se reproduzirem como classe (OLIVEIRA, 1981).

A analogia ao final da década de 1950 para pensar a Educação Profissional faz necessária diante do fato de que ao submeter os conteúdos da profissionalização oferecida na Rede Federal aos arranjos produtivos estabelecidos, inviabiliza-se a possibilidade de abrir a região (OLIVEIRA, 1981, p. 31). Não se diferencia da função histórica que a Educação Profissional vem cumprindo no Brasil ao longo da sua centenária história, mas também, revela o campo vencedor nas arenas internas do campo democrático popular e externas no âmbito da sociedade brasileira. Por outro lado, os arranjos produtivos locais estão agonizando devido a sucessivas políticas industriais redentoras cuja coloração ideológica agrega diferentes matizes, mas também, a terra arrasada sempre é um vasto campo de possibilidades.

A presença da Rede Federal de Educação Profissional e Tecnológica no território brasileiro é significativa e produziu fluxos e dinâmicas a espaços que há 20 anos seriam qualificados como opacos ou de pouca fluidez (SANTOS \& SILVEIRA, 
2001). Essa estrutura material tecnológica com o devido investimento público, associada a uma política de Estado que proteja a indústria nacional por meio do aumento das tarifas de importações de manufaturados e bens tecnológicos, associado a um novo pacto de classes no país, pode ser o caminho de um desenvolvimento nacional que se paute no consumo de seu imenso mercado interno e, ao mesmo tempo, possa pavimentar caminhos para avançarmos na perspectiva de continuarmos a travessia rumo a uma formação integral e integrada de uma sociedade onde o valor de uso tenha mais significado a que o valor de troca.

\section{Referências Bibliográficas}

ALVES, L. M. S., PLACIDO, R. L., FARIA F. P., ROHR, M. L. (2019). Retalhos de Experiências Exitosas em Educação Profissional e Tecnológica. Debates em Educação, 11(24), 564-585.

BOITO Jr., A. O golpe de 1954: a burguesia contra o populismo. São Paulo: Brasiliense, 1982.

BRANDÃO, C. Território e desenvolvimento: as múltiplas escalas entre o local e o global. Campinas: Editora da Unicamp, 2007.

DEAN, Warren. A industrialização de São Paulo (1880-1945). Tradução de Octávio Mendes Cajado. Rio de Janeiro: Bertrand Brasil, 1991.

ENGELS, F. A origem da família, da propriedade privada e do Estado. Tradução de Leandro Konder. Rio de Janeiro: Civilização Brasileira, 1974.

FANON, F. Os condenados da Terra. Tradução de José Laurênio de Melo. Rio de Janeiro: Civilização Brasileira, 1979.

FERNANDES, F. A revolução burguesa no Brasil: ensaio de interpretação sociológica. Rio de Janeiro: Zahar Editores, 1975.

GONÇALVES, M.F. Engrenagens da locomotiva: ensaio sobre a expansão urbana paulista. Campinas: Instituto de Filosofia Ciências Humanas (IFCH) UNICAMP, 1998. 339 p. Tese de doutorado, Programa de Pós Graduação em Sociologia. Campinas, SP, 1998.

GORENDER, J. O escravismo colonial. São Paulo: Editora Fundação Perseu Abramo, 2010.

LAFARGUE, P. O direito à preguiça. São Paulo: Hucitec/ Unesp, 1999.

MARTINS, J.S. O cativeiro da terra. São Paulo: Hucitec, 1979. 
MARX, K. O 18 Brumário de Louis Bonaparte. Coimbra, 1971.

MASSEY, Doreen. Pelo espaço: uma nova política da espacialidade. Rio de Janeiro: Bertrand Brasil, 2008.

OLIVEIRA, F. Elegia para uma Re(li)gião: SUDENE, Nordeste. Planejamento e conflitos de classes. 3. ed. Rio de Janeiro: Paz e Terra, 1981.

OLIVEIRA, F. Economia da dependência imperfeita. Rio de Janeiro: Paz e Terra, 1989.

OLIVEIRA, F. Crítica à razão dualista. O ornitorrinco. São Paulo: Boitempo, 2003.

PRADO Jr., C. Formação do Brasil Contemporâneo. 8. ed. São Paulo: Civilização Brasileira, 1965.

SANTOS, M. \& SILVEIRA, M. L. O Brasil: território e sociedade no início do século XXI. Rio de Janeiro: Record, 2001.

SANTOS, M. A natureza do espaço: espaço e tempo: razão e emoção. 3. ed. São Paulo: Hucitec, 1999.

SANTOS, M. Sociedade e espaço: formação social como categoria e como método. Boletim Paulista de Geografia, n. 54, p. 81 - 100, 1977.

SAVIANI, D. Histórias das ideias pedagógicas no Brasil. 4. ed. Campinas: Autores Associados, 2013.

SCHENKEL, C.A. Gestão ambiental: perfil profissional e formação em cursos superiores de tecnologia e de bacharelado. 2012. 348 f. Tese (Doutorado em Ciências Humanas) - Universidade Federal de Uberlândia, Uberlândia, 2012.

SINGER, P. A crise do milagre: interpretação crítica da economia brasileira. São Paulo: Paz e Terra, 1975.

SOUZA, J. A elite do Atraso: Da escravidão à Lava Jato. Rio de Janeiro: Leya, 2017. 


\section{Cloves Alexandre de Castro}

Blumenau, SC, Brasil

Doutor em Geografia Humana pela Universidade Estadual de Campinas-UNICAMP. Pós-Doutorado em Geografia na Universidade de São Paulo-USP, sob a supervisão da professora Marta Inez de Medeiros Marques. Foi professor do ensino público nos municípios de Descalva-SP e de São Paulo. Atuou no ensino médio privado nas cidades de Presidente Prudente-SP e São Paulo. É pesquisador e ativista dos cursinhos populares. Professor do Instituto Federal Catarinense (IFC-Blumenau) desde julho de 2016.

Email: cloves.castro@ifc.edu.br

Link do Lattes: http://lattes.cnpq.br/3122759041294108

\section{Reginaldo Leandro Plácido}

Blumenau, SC, Brasil

Doutorado em Educação pela Universidade Metodista de Piracicaba (2014) com doutoramento intercalar em História da Educação pela Universidade de Lisboa. Mestrado em História e Teologia pelo Instituto Ecumênico de Pós-Graduação em Teologia (2008). Professor EBTT do Instituto Federal Catarinense. Docente do Mestrado em Educação Profissional e Tecnológica do IFC. Diretor de Ensino do IFC. Avaliador ad hoc do Instituto Nacional de Estudos e Pesquisas Educacionais Anísio Teixeira. Coordenador do Grupo de Pesquisa e Estudos em Gestão, Políticas e História da Educação Profissional e Tecnológica (GPHEPT) - IF-Catarinense.

Email: reginaldo.placido@ifc.edu.br

Link do Lattes: http://lattes.cnpq.br/6754849438511308

\section{Cladecir Alberto Schenkel}

Blumenau, SC, Brasil

Doutorado em Educação pela Universidade Federal de Uberlândia (2012). É professor do ensino básico, técnico e tecnológico no Instituto Federal Catarinense (IFC). Atualmente, é Pró-Reitor de Pesquisa, Pós-Graduação e Inovação e docente permanente do Mestrado Profissional em Educação Profissional e Tecnológica em rede nacional, Polo IFC/Blumenau.

Email: cladecir.schenkel@ifc.edu.br

Link do Lattes: http://lattes.cnpq.br/0498855225969004

Recebimento: 19/07/2020

Aprovação: 15/09/2020

\section{Q.Code}


Revista Labor

Programa de Pós-graduação em Educação, Universidade Federal do Ceará

Fortaleza-CE-Brasil

\section{Editores-Responsáveis}

Prof. Dr. Enéas de Araújo Arrais Neto, Universidade Federal do Ceará - UFC, Brasil

Prof. Dr. Arno Münster, Universidade de Amiens - Paris, França 